\title{
Harnessing Value From Circular Economy
}

\author{
$1^{\text {st }}$ Kirsikka Kiviranta \\ VTT Technical Research Centre of Finland Ltd \\ Jyväskylä, Finland \\ kirsikka.kiviranta@vtt.fi \\ $3^{\text {rd }}$ Jonne Hirvonen \\ VTT Technical Research Centre of Finland Ltd \\ Jyväskylä, Finland \\ jonne.hirvonen@vtt.fi
}

\author{
$2^{\text {nd }}$ Tomi Thomasson \\ VTT Technical Research Centre of Finland Ltd \\ Jyväskylä, Finland \\ tomi.thomasson@vtt.fi \\ $4^{\text {th }}$ Matti Tähtinen \\ VTT Technical Research Centre of Finland Ltd \\ Jyväskylä, Finland \\ matti.tahtinen@vtt.fi
}

\begin{abstract}
Energy systems with high shares of variable renewable power generation have an increased need for power system flexibility. In parallel, renewable energy has an important role in circular economy as circular activities such as material processing consumes power and heat. This paper examines if harnessing flexibility from circular economy processes related to upgrading of side and waste material flows increase the value of a renewable energy system. Analysis is conducted on a selected case region as the availability of both circular processes and renewable energies are region-specific depending of the local characteristics. The potential of circular economy as a demand source for abundant variable renewable energy supply is compared to a highly electrified transportation sector and to power-to-heat conversion in addition to the baseline scenario. The analysis is performed with a developed mixed integer linear programming (MILP) model in which energy system operation and selected circular material flows are simultaneously optimized.
\end{abstract}

Keywords—circular economy, wind power, variability, flexibility

\section{INTRODUCTION}

The targets of Paris Agreement [1] and national and international policies of climate change mitigation along with continuously decreasing costs of variable renewable energy (VRE) technologies [2] are driving a transition in which renewable energy is substituting fossil fuels in energy systems throughout the globe. However, the current pace of the transition is not adequate to meet the long-term emission reduction targets [3]. Directing renewable energy investments to regions where energy yield can be maximized is vital to ensure sufficient progress in the adoption of renewable energies [4]. However, large-scale deployment of intermittent renewable energy sources, primarily wind and solar, challenges the power grid due to mismatches in power supply and demand, increasing the need of power system flexibility [5]. Flexibility can be increased by adopting variety of different measures such as market regulation, flexible demand and generation, transmission networks, pumped hydro and thermal energy storages, and hydrogen or synthetic fuel production via power-to-X technologies [6][7][8]. Alternatively, power surpluses could be applied to produce energy-intensive intermediate products to attain value [9]. By applying low-cost power surpluses in energy-intensive conversions of side and waste materials to higher-value products, renewable energy transition could foster investments on circular economy due to increased process profitability. In parallel, if the energy system attains additional value from the products processed from regional side and waste materials, circular economy could also increase cost competitiveness of the renewable energy system and hence accelerate investments on variable renewable energy. As the conjunction of large-scale deployment of variable renewable energy and circular economy could have mutual interests, the potential coupling of VRE generation and circular economy seems promising. Therefore, the objective of this study is to evaluate the feasibility of circular economy as a value-increasing element in a renewable energy system.

As the availability of both renewable energies and circular processes are local, depending of the regional characteristics, the potential of circular economy in increasing the value of a renewable energy system is evaluated in a selected case region. Due to clear system boundaries and small scale, islands have compelling nature for VRE integration studies [10][11]. Åland Islands, an autonomous archipelago located in the Gulf of Bothnia of the Baltic Sea, is aiming to transform its energy sector fully renewable by 2025 [12]. Due to the near term plans of extensive wind capacity additions [13], the energy system of Aland Islands has attained research interest and hence has been applied as a case platform in several studies concerning large-scale integration of variable renewable energy [10][11][14] [15]. Highly electrified transportation sector, synthetic fuel production and sector coupling between power and district heating systems are examples of the studied options to enhance the integration of VRE supply in the region. In this study, the potential of circular economy in increasing the value of the renewable energy system is studied and compared to a Baseline scenario built for the year 2025. In addition, the flexibility of circular economy as a power demand source for abundant VRE supply is compared to highly electrified transportation sector and power-to-heat conversion.

\section{METHODOLOGY}

\section{A. Scenario setup}

The energy system under study concerns both power and district heating sectors of Aland Islands and is described in [16]. The modelled energy system is maintained constant in all scenarios while the demand source for abundant VRE generation varies between the scenarios. The Baseline scenario represents the energy system of Alland Islands in which the planned wind 
projects [13] are completed and hence wind capacity is increased from current $21 \mathrm{MW}$ to $185 \mathrm{MW}$. Furthermore, an additional investment on a $15 \mathrm{MW}$ residential solar PV capacity is made. District heat production capacity consists of two existing heat production units fueled by forest residues with capacities of $11 \mathrm{MW}$ and $5 \mathrm{MW}$ (thermal efficiency $86 \%$ ) in addition to transportable heating units totaling in $45 \mathrm{MW}$ (thermal efficiency $88 \%$ ), which are fueled by heavy fuel oil [17]. For modelling purposes, the two existing high voltage power transmission lines from Åland Islands to Sweden and Finland are aggregated into one line with total capacity of $180 \mathrm{MW}$ [18]. In the Baseline scenario, VRE supply exceeding local power demand is exclusively exported outside the island through the transmission lines to the neighboring power areas of Sweden and Finland.

To study abundant VRE integration potential of circular economy, side and waste material streams with potential for value upgrading must be selected for further evaluation from the case region. The circular material processing pathway in this study converts biodegradable waste into biomethane. In P2CE scenario, biodegradable wastes, currently largely composted in Åland Islands [19], are converted into biogas in a new biogas plant. The amount of biodegradable waste in Alland Islands is evaluated to be 35000 tons corresponding to constant hourly biogas yield of $378 \mathrm{~m}^{3}$ with methane concentration at $63 \%$ with the remaining flow consisting mainly of carbon dioxide $\left(\mathrm{CO}_{2}\right)$ [19]. The study estimates the investment cost for the new biogas plant to be $6.6 \mathrm{M} €$. For this study, fixed operating and maintenance costs of $7 \%$ of CAPEX, lifetime of 25 years and weighted cost of capital (WACC) of $7 \%$ are applied. For the purpose of this study, the resulting biogas can be further upgraded to biomethane and the separated carbon dioxide flow can be further converted to synthetic natural gas ( $\mathrm{SNG}$ ) which is equivalent to biomethane. The process is referred as biological methanation [20], in which carbon dioxide is first separated from the raw biogas flow and then combined with hydrogen $\left(\mathrm{H}_{2}\right)$ derived from electrolyser. The resulting product is synthetic natural gas, which is added to the purified biomethane flow. Electrolyzer capacity of $2.5 \mathrm{MW}_{\mathrm{e}}$ (efficiency 67\%) is chosen to enable full conversion of hourly carbon dioxide supply $(274 \mathrm{~kg} / \mathrm{h})$ from raw biogas to SNG at full load. An intermediate hydrogen storage to store hydrogen production of one hour $(1.67 \mathrm{MW})$ is placed between electrolysis and methanation processes to partly decouple hydrogen production from the methanation process. The product price of biogas is assumed to be $60 € / \mathrm{MWh}$ whereas the price of biomethane is set at $80 € / \mathrm{MWh}$ in accordance to [20]. Biomethane is applied in the transportation sector to replace the usage of fossil fuels. To estimate the avoided carbon dioxide emissions, annual gasoline and diesel demand are set at $117 \mathrm{GWh}$ and $104 \mathrm{GWh}$, respectively in accordance to the fuel consumption trends of the past decade in Aland Islands [21]. The default emission factors of carbon dioxide for the transportation fuels are obtained from [22].
P2EV scenario features electric vehicles (EVs) as an alternative power demand node in a highly renewable energy system. The charging of electric vehicles occurs as a dump charge and therefore, bidirectional charging from the vehicle to the grid is not considered in this study. The study assumes that $25 \%$ of the passenger cars in Åland Islands will be fully electric, resulting in 5960 electric vehicles by 2025 . The daily estimated power demand for electric vehicles is set at $8.2 \mathrm{kWh}$ based on average electricity consumption $(0.2 \mathrm{kWh}$ [23]) and estimated daily transportation demand (41 km [24]) for each vehicle. The vehicles are allowed to be charged during night hours between a time window of 23 and 05 with a maximum hourly charging limit of $3.8 \mathrm{~kW}$ [25] per vehicle.

The $\mathrm{P} 2 \mathrm{H}$ scenario studies the feasibility of heat pumps as an additional power demand node to balance variable power generation. In addition to providing demand flexibility, heat pumps also enable to phase out fossil fuels in the district heating sector by partly electrifying the heat supply. As applicable low-temperature waste heat sources for large-scale industrial heat pump deployment was not identified in Åland Islands, residential air-to-air heat pumps, totalling $15 \mathrm{MW}$ with a coefficient of performance (COP) of 3 , are selected for the evaluation.

The capital expenditures for the new power generation investments in wind and solar capacity as well as to electrolysis, biological methanation and hydrogen storage are presented in Table 1 . The costs are annualized by applying WACC of 7\%.Hourly input time series data including scaled time series for both power (350 GWh/a) and district heat demand (132 GWh/a) for the year 2025 in Åland Islands and hourly production profiles for both wind and solar are obtained from [16]. The power demand for electrolysis, electric vehicles and heat pumps are accounted separately based on the defined unit models and assumptions. Hourly spot market prices for the modelled area are obtained from Nord Pool SE3 market area from 2017 [27]. The average district heat price is set at $80 € / \mathrm{MWh}$ [28]. For heat production, the forest residue price is set to $22 € / \mathrm{MWh}$ and heavy fuel oil price to $45 € / \mathrm{MWh}$ [29]. The price of $\mathrm{CO}_{2}$ emission allowances is set to $30 € / \mathrm{t}$ [30].

\section{B. Simulation model}

A combined scheduling and capacity planning model developed at VTT and used in [16] is applied in this study for combined optimization of energy system operation and selected material flows. The applied model is a mixed integer linear programming (MILP) model considering annual operation at hourly resolution. The model determines the optimal operation of the energy system by seeking the minimum system operating cost, including variable system operating costs, fuel costs, taxes as well as capital costs of additional unit investments. In this study, the model simultaneously optimizes the energy system and unit models of the selected circular economy processes while respecting the defined system constraints defined for each scenario. Figure 1 shows the components and alternative flows of energy applied in the model in this study. 
Table 1. Economic parameters for new power generation and circular economy investments.

\begin{tabular}{|c|c|c|c|c|}
\hline Process & $\begin{array}{c}\text { CAPEX } \\
\epsilon / k W \\
\end{array}$ & $\begin{array}{l}\text { Fixed OPEX } \\
\text { \% of CAPEX }\end{array}$ & Lifetime & Source \\
\hline Onshore wind & 975 & 2.3 & 30 & [26] \\
\hline Offshore wind & 1300 & 2.3 & 30 & Assumption based on [10] \\
\hline Solar PV & 715 & 1.4 & 30 & [26] \\
\hline Electrolysis & $1230^{1}$ & 2.5 & 20 & [20], [26] \\
\hline Biological methanation & $730^{2}$ & 2.5 & 20 & [20] \\
\hline Hydrogen storage & $13.5^{3}$ & 0.14 & 30 & [26] \\
\hline
\end{tabular}

\section{RESULTS AND DISCUSSION}

The breakdown of cost and income flows for the evaluated scenarios is presented in Figure 2. With the applied assumptions and selected system boundaries, the annual system net profit for all scenarios is net negative (Baseline, -2.09 M€; P2CE, -2.03 M€; P2EV, -2.16 M€ and $\mathrm{P} 2 \mathrm{H},-0.38 \mathrm{M} €)$. It must be yet noted that no feed-in tariffs nor subsidies for renewable generation are considered in this study. From the system viewpoint, the P2CE scenario is economically slightly more feasible than the Baseline scenario despite the additional investments. In P2CE, the additional value for the energy system is derived from the fuels obtained from the processed side and waste material streams.

The most feasible scenario economically from the system viewpoint is $\mathrm{P} 2 \mathrm{H}$, in which heat pumps are applied as an additional power demand node. However, in the scenario, the additional investments are assumed to be made by consumers and are not hence accounted in the annualized investment costs. In the P2CE scenario, the annualized investment and operating costs of the biogas plant totalling in 1.0 M€ decrease the feasibility of the scenario notably. If the biogas plant was assumed to be already present in the system, the annual system net profit of the scenario would increase to $-0.9 \mathrm{M} €$, however still being less feasible than $\mathrm{P} 2 \mathrm{H}$. When compared to Baseline, the P2CE scenario is only marginally more feasible, and therefore relies on the price assumptions. For example, if the price of upgraded biogas is decreased from $80 € / \mathrm{MWh}$ to $75 € / \mathrm{MWh}$, the scenario becomes economically less feasible.

The circular ecosystem in the P2CE scenario is financially profitable due to the high annual income derived from sold fuels including biogas and biomethane (2.1 M€/a), as seen from Figure 3. An additional income from sold district heat (0.3 M€/a) can also be derived assuming that the waste heat from the electrolyser can be integrated to the district heating network. The circular ecosystem does not however reach its full operating potential. In the scenario, the electrolyzer consumes $13.2 \mathrm{GWh}$ of electricity, although the theoretical potential is 21.9 GWh, assuming constant full load operation. This, on the other hand, shows the capability of the process to act as a flexible power demand node in the renewable energy system, as the process is operating according to the availability of low-cost power surpluses.

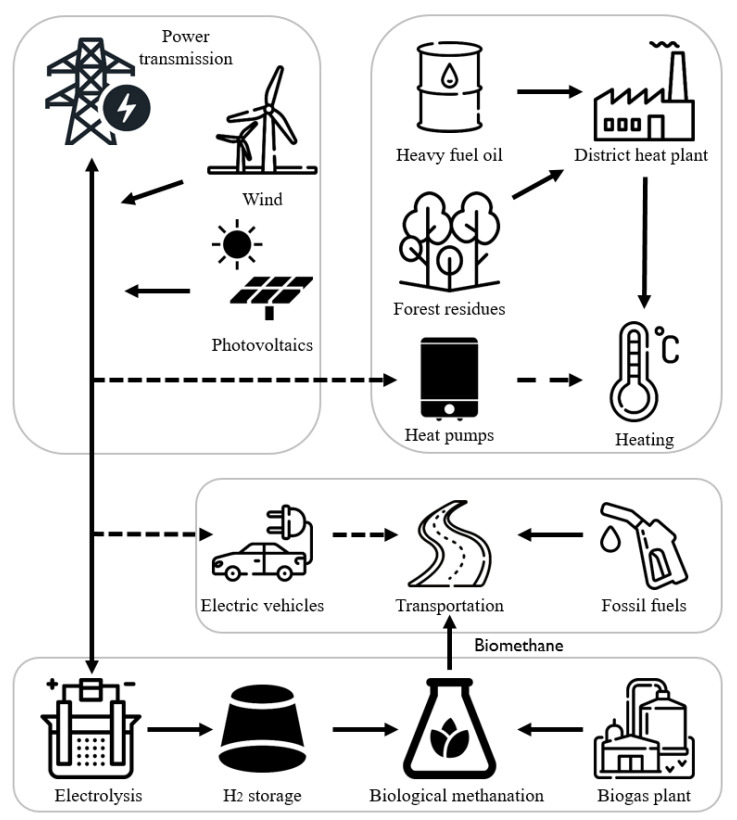

Figure 1. Key components and flow chart of the energy and material flows applied in the optimization model. The dashed line defines the scenarios alternative to circular economy.

Differences in the abundant VRE utilization potential between the alternative scenarios are presented in Figure 4. The circular economy pathway consumes the least electricity out of the studied scenarios (13.2 GWh). However, the power consumption in the scenario is seasonally relatively constant. The electrolyzer is only dependent of the VRE supply, as the biogas to be upgraded is assumed to be produced continuously throughout the year. Furthermore, the operational flexibility is also increased due to the available hydrogen storage. 
Heat pumps in the $\mathrm{P} 2 \mathrm{H}$ scenario lead to the highest electricity consumption (21.1 GWh). However, the consumption varies notably seasonally, being dependent on the district heat demand. The seasonal variation also indicates that heat pumps would be able to provide peak heating instead of the oil heating boilers. In the P2EV scenario, the power consumption is constrained by the hourly maximum limit and limited allowed charging hours, leading to two distinct power consumption levels. When comparing the studied scenarios, it should be noted that the P2CE scenario has the most realistic setup. The biogas production potential and consequently the hydrogen production are constrained based on real estimates of biodegradable waste streams in Alland Islands, whereas the number of electric vehicles and heat pumps in the $\mathrm{P} 2 \mathrm{EV}$ and $\mathrm{P} 2 \mathrm{H}$ scenarios are purely speculative based on simple assumptions.

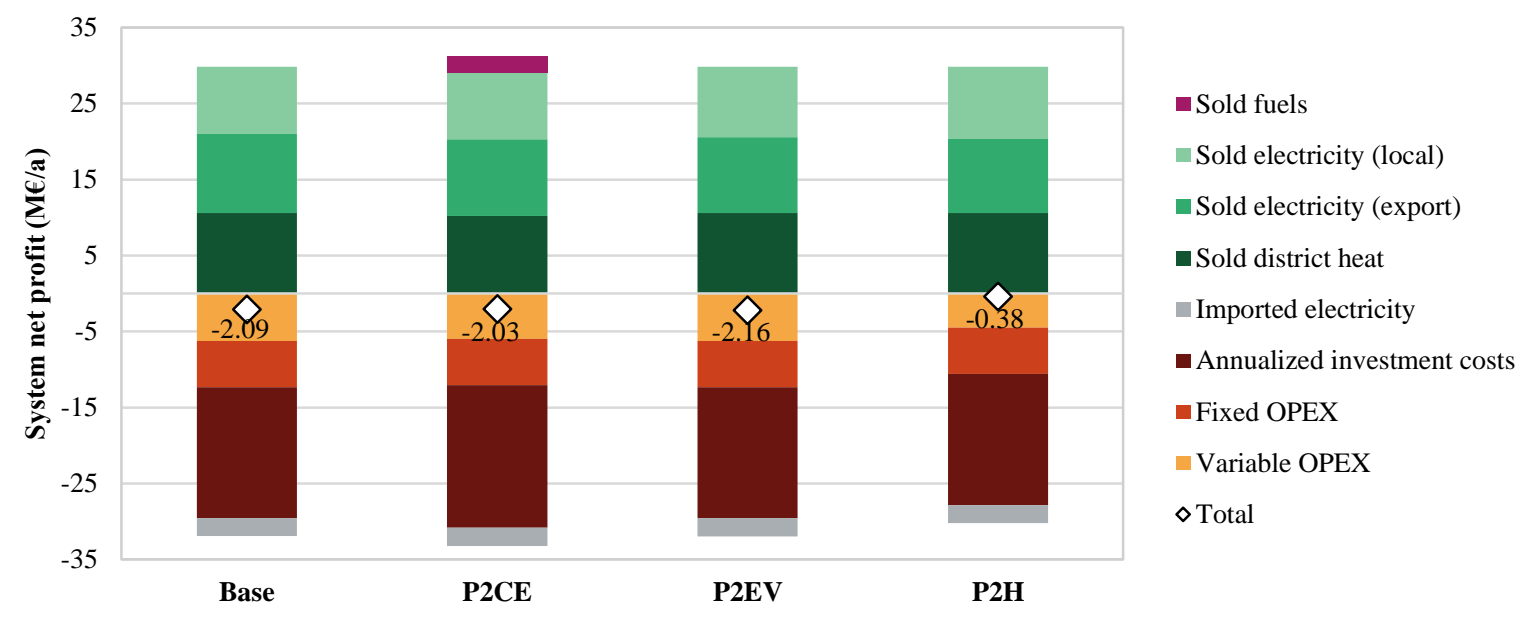

Figure 2. Breakdown of annual cost and income flows of the evaluated scenarios.

Besides economics, the alternative scenarios bring out environmental benefits. Figure 5 displays the annually generated $\mathrm{CO}_{2}$ emissions within the defined boundaries of transport and heating sectors for the studied scenarios. All the alternative scenarios lead to emission reductions compared to Baseline scenario (total $60 \mathrm{kt} / \mathrm{a}$ ), with the greatest reductions being achieved in P2EV (total $47 \mathrm{kt} / \mathrm{a}$ ), which directly reduces emissions from the transport sector.
The emissions reductions are estimated by assuming that the produced biomethane in $\mathrm{P} 2 \mathrm{CE}$ scenario and electric vehicles in P2EV scenario replace fossil fuel consumption in the transport sector, whereas heat pumps in $\mathrm{P} 2 \mathrm{H}$ can reduce oil consumption in district heat production. In the $\mathrm{P} 2 \mathrm{CE}$ scenario, small $\mathrm{CO}_{2}$ reductions are also achieved in the heating sector as waste heat from the electrolyzer replaces heat production from the oil boilers.

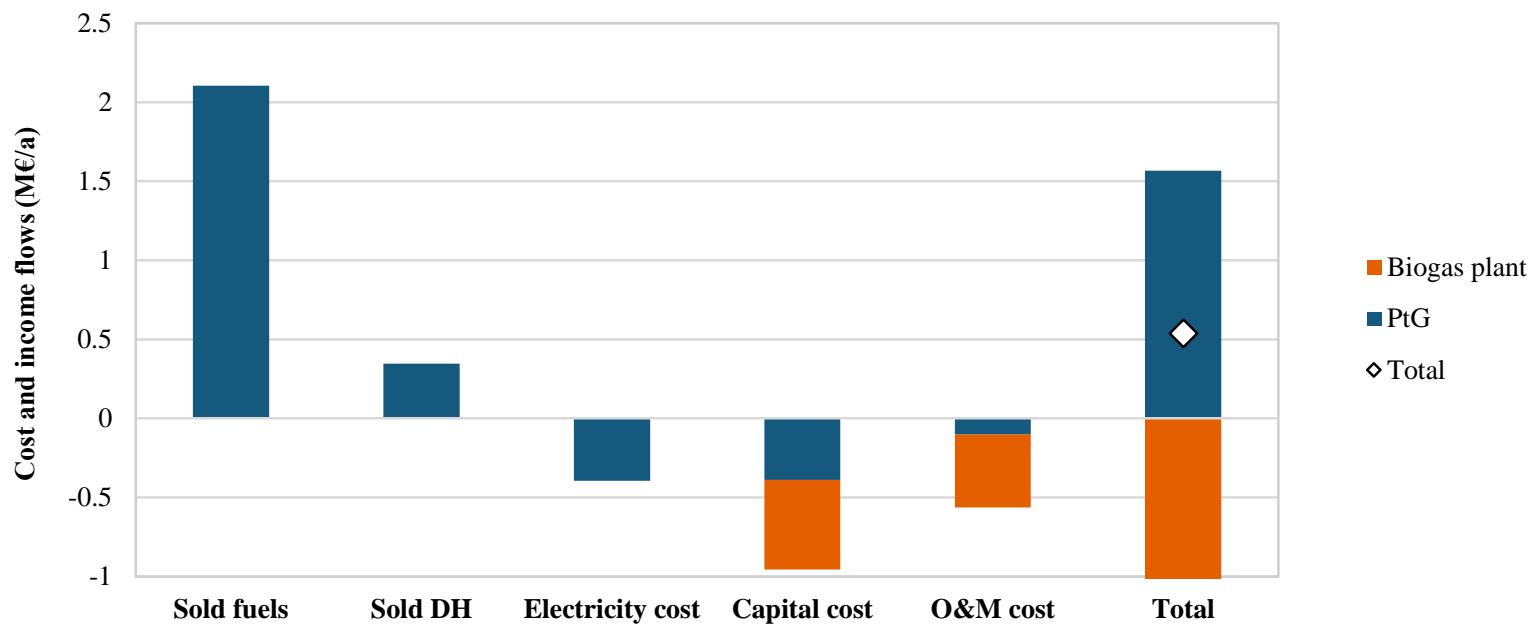

Figure 3. Breakdown of annual cost and income flows of the circular ecosystem in the P2CE scenario. 
P2CE: 13.2 GWh

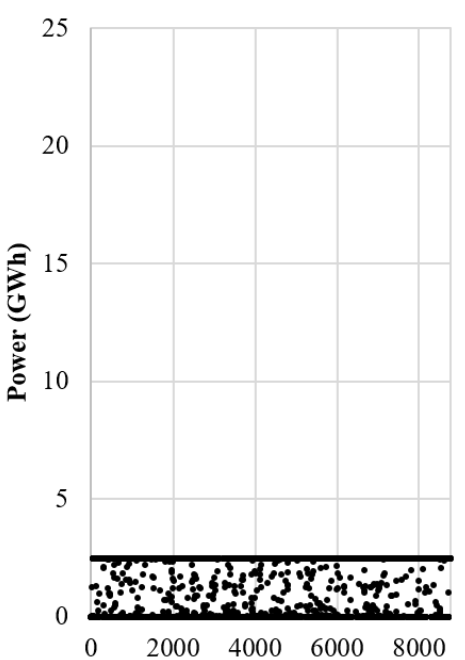

P2EV: 19.6 GWh

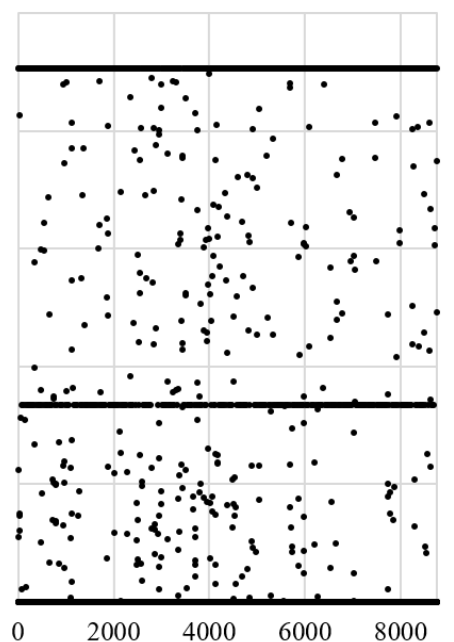

P2H: 21.1 GWh

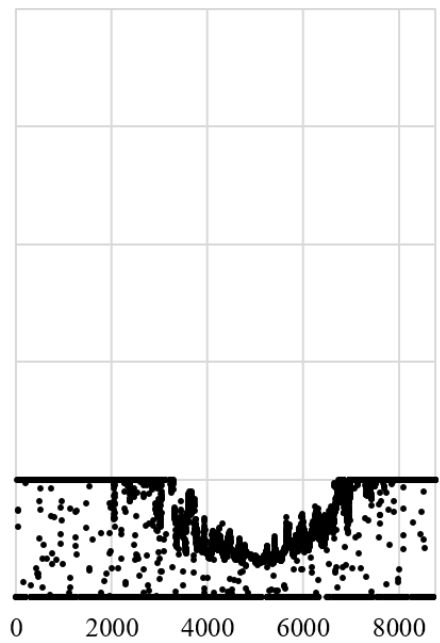

Figure 4. Hourly electricity use of the added power demand sources in the different scenarios.

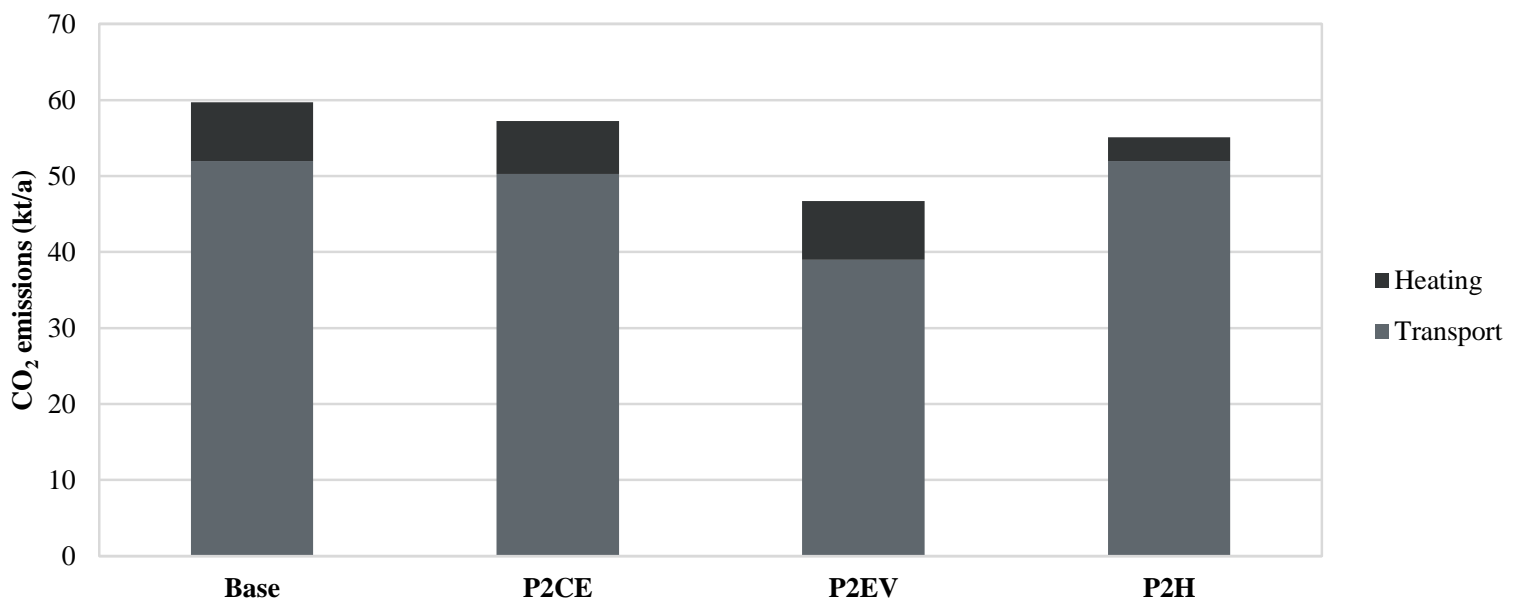

Figure 5. Annual $\mathrm{CO}_{2}$ emissions from transport and heating sectors in the different scenarios.

\section{CONCLUSIONS}

The study finds that circular economy can increase the value of a renewable energy system as low-cost power surpluses can be applied to upgrading processes of side and waste material streams to attain higher value products. The profitability of the circular pathway in this study was largely based on the income derived from the sold fuels with small income contribution provided by the sales of district heat. The circular process in the study was found to be capable to operate according to the availability of variable power supply. Therefore, the circular process acted as a consumption source for abundant VRE generation and increased the integration of VRE to the regional energy system.

With the applied assumptions and system boundaries of the study, heat pumps were found to be economically more feasible approach to integrate VRE from the system viewpoint than circular economy. Furthermore, both heat pumps and electric vehicles integrated more VRE to the system when compared to the circular processes, with distinctly different consumption profiles. However, comparing the integration potential contains some uncertainty, as the capacity of both heat pumps and electric vehicles were estimated based on simple assumptions, whereas the circular ecosystem was constructed based on the actual biomethane production potential in the region. Furthermore, the scenarios are also different economically. Unlike the investments on biogas plant and to the further production chain for biomethane production, the investments on heat pumps and electric vehicles were dependent on consumers and therefore were not accounted in the annual system cost.

The study proves that the conjunction of variable renewable energy and circular economy can have mutual benefits from the system perspective. In this study, low-cost wind energy during periods of abundant VRE supply made the selected circular process profitable. Simultaneously, the products derived from the circular ecosystem were able to 
increase the annual system net profit of the energy system despite the additional investments on the circular processes.

\section{ACKNOWLEDGMENT}

The research for this paper was carried out as a part of VTT's research program "Circular Economy Concepts". The authors and grateful for the financial support.

\section{REFERENCES}

[1] United Nations, "Paris Agreement," 2015

[2] IRENA, "Renewable Power Generation Costs in 2018," International Renewable Energy Agency, Abu Dhabi, 2019.

[3] IRENA, Global Energy Transformation: A roadmap to 2050. Abu Dhabi: International Renewable Energy Agency, 2018

[4] R. Lantto et al., "Commentary Going Beyond a Circular Economy: A Vision of a Sustainable Economy in Which Material, Value and Information Are Integrated and Circulate Together," Ind. Biotechnol., vol. 15, no. 1, 2019.

[5] IRENA, Power system flexibility for the energy transition, Part 1: Overview for policy makers. Abu Dhabi: International Renewable Energy Agency, 2018.

[6] J. Cochran et al., "Flexibility in 21st Century Power Systems," 2014.

[7] P. D. Lund, J. Lindgren, J. Mikkola, and J. Salpakari, "Review of energy system flexibility measures to enable high levels of variable renewable electricity," Renew. Sustain. Energy Rev., vol. 45, pp. 785-807, 2015.

[8] S. Paiho et al., "Increasing flexibility of Finnish energy systems - A review of potential technologies and means," Sustain. Cities Soc., vol. 43, no. February, pp. 509-523, 2018.

[9] R. Lantto et al., "Going beyond a circular economy," Espoo, 2018.

[10] M. Child, A. Nordling, and C. Breyer, "Scenarios for a sustainable energy system in the Åland Islands in 2030," Energy Convers. Manag., vol. 137, pp. 49-60, 2017.

[11] M. Child, "The Impacts of High V2G Participation in a 100 \% Renewable Åland Energy System,” Energies, vol. 11, pp. 1-19, 2018

[12] J. Parkkari, “Ahvenanmaasta Suomen seuraava vientimenestys? Maakunta siirtyy uusiutuvaan energiaan, ja malli halutaan myydä Kiinaan ja Intiaan," YLE, 2018. [Online]. Available: https://yle.fi/uutiset/3-10127907. [Accessed: 22-Oct2018].

[13] Allwinds Ab, "The Wind Power of Åland Islands," 2018.
[14] A. Pääkkönen and T. Joronen, "Revisiting the feasibility of biomass-fueled CHP in future energy systems - Case study of the Åland Islands," Energy Convers. Manag., vol. 188, pp. 66-75, May 2019.

[15] K. Kiviranta, "Vision for 100\% renewable Åland Islands," University of Oulu, 2019.

[16] K. Kiviranta, T. Thomasson, J. Hirvonen, and M Tähtinen, "Connecting circular economy and energy industry: a case study for Åland Islands (Unpublished)," 2020.

[17] Finnish Energy, "District heating statistics," 2018 [Online]. Available: https://energia.fi/en/news_and_publications/publicatio ns/district_heating_statistics.html\#material-view. [Accessed: 15-Oct-2018].

[18] CLIC Innovation, "Final joint report of the projects FLEXe DEMO and CEMBioFlex," 2019.

[19] M. Allerborg, J. Bergström, J. Englöf, J. Holroyd, C. Hultin, and O. Reuter, "Rötning av bioavfall på Åland," Stockholm, 2015.

[20] S. Kouri, M. Hurskainen, J. Kärki, E. Tsupari, E. Alakangas, and C. Bajamundi, "Integrated utilisation pathways for biogenic carbon dioxide in biomass driven industry sectors," Eur. Biomass Conf. Exhib. Proc., vol. 2017, no. 25thEUBCE, 2017.

[21] ÅSUB, "Försäljningen av några vanliga oljeprodukter på Åland 1982-2017,” 2019. [Online]. Available: https://www.asub.ax/sv/miljo-och-energi-miljo-ochenergi. [Accessed: 20-Aug-2019].

[22] Statistics Finland, "Fuel classification 2020," 2020 [Online]. Available: https://www.stat.fi/tup/khkinv/khkaasut_polttoaineluo kitus.html.

[23] M. Ruska, J. Kiviluoma, and G. Koreneff, Sähköautojen laajan käyttöönoton skenaarioita ja vaikutuksia sähköjärjestelmään. 2010.

[24] Finnish Transport Infrastructure Agency, "Henkilöliikennetutkimus 2016," Helsinki, 2018.

[25] M. Paakkinen, M. Pihlatie, V. Peltola, and P. Pylsy, "Sähköautojen kotilataaminen: GASELLI-väliraportti 1. (Tutkimusraportti; Nro VTT-R-02416-18)," 2018.

[26] J. Ikäheimo, E. Pursiheimo, J. Kiviluoma, and H. Holttinen, "Role of power to liquids and biomass to liquids in a nearly renewable energy system," IET Renew. Power Gener., vol. 13, no. 7, pp. 1179-1189, May 2019.

[27] Nordpool, "Historical Market Data," 2018. [Online]. Available: https://www.nordpoolgroup.com/historicalmarket-data/. [Accessed: 15-Aug-2019].

[28] Finnish Energy, "District heating in Finland 2017," 2018.

[29] Statistics Finland, "Statistics: Energy prices," 2018. [Online]. Available: http://www.stat.fi/til/ehi/2018/02/ehi_2018_02_201809-12_tie_001_en.html. [Accessed: 23-Nov-2018]. 
[30] EEX, "European Emission Allowances (EUA)," 2019.

[Online]. Available: https://www.eex.com/en/marketdata/environmental-markets/auction-market/europeanemission-allowances-auction\#!/2019/12/10.

[Accessed: 10-Dec-2019]. 